\title{
Using AFLP Markers for the Analysis of the Genetic Diversity of Apricot Cultivars in Tunisia
}

\author{
Lamia Krichen \\ Laboratoire de Génétique Moléculaire, Immunologie et Biotechnologie, Faculté des Sciences de \\ Tunis, Campus Universitaire-Tunis-El Manar, 2092, Tunisia, and Institut National de Recherche \\ Agronomique, UR1052 Unité de Génétique et Amélioration des Fruits et Légumes, Centre de \\ Recherches d'Avignon-Domaine Saint Maurice, 84143 Montfavet Cedex, France
}

Joao M.S. Martins

Departamento de Proteç̧ão das Plantas, Estação Agronómica Nacional, 2784-505 Oeiras, Portugal

Patrick Lambert

Institut National de Recherche Agronomique, UR1052 Unité de Génétique et Amélioration des Fruits et Légumes, Centre de Recherches d'Avignon-Domaine Saint Maurice, 84143 Montfavet Cedex, France

\begin{abstract}
Abderrazzak Daaloul
Institut National Agronomique de Tunisie, 43 Avenue Charles Nicole, 1002 Tunis-Belvédère, Tunisia, and Ministère de l'Agriculture et des Ressources Hydrauliques, 30 Avenue Alain Savary, 1002 Tunis-Belvédère, Tunisia

Neila Trifi-Farah and Mohamed Marrakchi

Laboratoire de Génétique Moléculaire, Immunologie et Biotechnologie, Faculté des Sciences de Tunis, Campus Universitaire-Tunis-El Manar, 2092, Tunisia

Jean-Marc Audergon ${ }^{1}$

Institut National de Recherche Agronomique, UR1052 Unité de Génétique et Amélioration des Fruits et Légumes, Centre de Recherches d'Avignon—Domaine Saint Maurice, 84143 Montfavet Cedex, France
\end{abstract}

Additional INDEX WORDs. Prunus armeniaca, phylogeny, molecular fingerprinting, geographic origin

Abstract. Apricot (Prunus armeniaca L.) culture is present in a wide range of areas and microclimates in Tunisia. Each of them contains several specific cultivars and shows a high level of morphological diversity. To characterize the related diversity, surveys were performed in the four main apricot cultivation areas, where 31 cultivars representing apricot landraces were sampled. DNA was extracted and amplified with five different EcoRI-MseI AFLP primer combinations. Autoradiographs revealed 203 polymorphic markers in a total of 295 detected fragments. A set of redundant marker patterns was identified and deleted from the binary data matrix, data analysis being performed on a total of 167 polymorphic markers. In a dendrogram calculated by the Ward clustering technique, two major groups were identified, separating nine cultivars from the other 22 . Three subgroups have been revealed in each of the main groups. The groups and subgroups identified on the genetic basis are closely related to the geographic origin of the cultivars. Analysis of the actual repartition suggested at least the introduction of two independent gene funds in the northern and central prospected areas, followed by a local diversification and then a dissemination phase. Their interaction occurred at least in the two sites of Testour and Sbikha.

Received for publication 18 Apr. 2007. Accepted for publication 12 Oct. 2007. This work is partially supported by the French-Tunisian Cooperation (Project $\mathrm{CMCU}$ ) and the Tunisian Ministry of Higher Education, Scientific Research and Technology (General Directorate for Scientific Research and Technological Modernization).

Local names of cultivars have been transliterated into the Roman alphabet following the rule established in Article 30.2 of the International Code of Nomenclature for Cultivated Plants, 7th ed. (International Union of Biological Sciences, Commission for the Nomenclature of Cultivated Plants, 2004).

The authors thank the Tunisian Ministry of Agriculture and Hydraulic resources through the Regional Committees for Agricultural Development and particularly the General Direction of Agricultural Production for their kind assistance along the survey phase in the identification of the local cultivars. The authors also thank Jules Janick, Department of Horticulture \& Landscape Architecture at Purdue University and Michel Pitrat and Rebecca Stevens (INRA UR1052) for their critical reading of the manuscript.

'Corresponding author. E-mail: jma@avignon.inra.fr. or audergon@avignon. inra.fr.
Apricot is a stone fruit species with a remarkable adaptation to several environmental conditions, ranging from the mild winter climate of northern Africa where apricots have low chilling requirements, to the freezing winter climate of Russia and other Asian countries, where only cultivars with high chilling requirements are encountered (Faust et al., 1998). Apricots are grown throughout Asiatic and European countries, all around the Mediterranean Basin, as well as in America, Australia, and New Zealand. Despite of this versatility as a species, most cultivars are restricted to their own particular regions (Crossa-Raynaud, 1960). Thus, each area of apricot culture, even inside a single country, represents one reservoir of genetic diversity.

In Tunisia, several local cultivars exist, which seem to be circumscribed to different areas of cultivation. This fact is at the 
origin of a multitude of cultivars names and types, which led us to suppose that the diversity of the apricot germplasm in this country is rather large. Tunisian apricot material can be divided in three main categories: oasian local types propagated by seeds, traditional local cultivars, and recently developed cultivars mainly issued from breeding programs, the latter two propagated by grafting. The present work deals with the characterization of the traditional local cultivars.

The existence of many of these apricot cultivars is threatened because they recently began to loose their economic importance; for that reason, farmers adopted cultivars of high market demand or shifted to other, more profitable crops. In recent years, several works have focused on the identification, collection, and characterization of Tunisian apricot cultivars (European Commission International Cooperation for Developed Countries, 2002; Krichen, 2001), to elaborate a national core collection and to preserve these genetic resources.

Several works have been published on apricot morphological diversity (Badenes et al., 1998; Balta et al., 2002; Krichen, 2001; Pérez-González, 1992) as well as on its molecular diversity (Battistini and Sansavini, 1991; Byrne and Littleton, 1989; Gogorcena and Parfitt, 1994; Hormaza, 2001; Takeda et al., 1998; Zhebentyayeva et al., 2003). Amplified fragment length polymorphism (AFLP) molecular markers were chosen for their distribution through the whole genome as was evidenced by Lambert et al. (2004) in apricot, and their potentially high polymorphism enabling a possible phylogeographic analysis (De Vienne, 1998; Desprès et al., 2003). They were demonstrated to be very powerful for assessing species diversity in Prunus L. such as peach [Prunus persica (L.) Batsch] (Aranzana et al., 2003; Manubens et al., 1999) and cherry [Prunus avium (L.)] (Tavaud et al., 2004). Several publications dealt with the analysis of the diversity of apricot using AFLP markers and have produced some insights on its taxonomic structure in the Mediterranean Basin (Geuna et al., 2003; Hagen et al., 2002; Hurtado et al., 2002).

This work extends the previous work to the Tunisian area. It aims to explore the diversity encountered in 31 traditional apricot cultivars issued from four apricot cropping areas to analyze the germplasm structure and its relationship with geographic origin of cultivation.

\section{Materials and Methods}

Plant material. This study has been focused on the traditional apricot landraces surveyed in northern and central areas of Tunisia. Plant material has been selected to maximize the observed diversity (Krichen, 2001), according to their morphological characteristics and information. Surveys were conducted in the northern and central areas of apricot culture in Tunisia corresponding to Ras Jbel and Testour in the north, Kairouan (where three areas were targeted: Sbikha, Dhraa Tammar, and Khit El Oued), and Mahdia and Sfax in the center. Surveyed areas belong to the subhumid climate for northern areas and to the arid climate for central areas. Two main cultural systems are encountered in Tunisian orchards: 1) the "intensive" system, characterized by a single species planted in the orchard; and 2) the "promiscue" system (Ribeiro, 1986), used in the Mediterranean area and characterized by the superposition of different vegetative strata using different fruit tree species.

A total of 31 local apricot cultivars were sampled (Fig. 1). These cultivars represent genotypes propagated by grafting and collected in traditional orchards from these cultivation areas. This sample of Tunisian apricot cultivars is representative of the well-known observed morphological diversity and includes a large variation in maturity period, shape of fruit, color of flesh, sweetness of kernel, taste, and aroma, as shown in Table 1 (Krichen et al., 2006).

Samples of young, fresh leaves were collected on a representative tree of each cultivar, except for the cultivar Banqī, for which samples were collected from two different orchards. The collected young leaves were stored at $-80{ }^{\circ} \mathrm{C}$ before DNA extraction.

Molecular anAlysis. Total DNA was extracted according to the maxi-prep protocol described by Bernatzky and Tanksley (1986). DNA was restricted by EcoRI and MseI endonucleases. Five AFLP primer combinations (EcoRI, MseI) (Hagen et al., 2002) with three selective nucleotides were selected for the specific amplifications according to Vos et al. (1995) with a

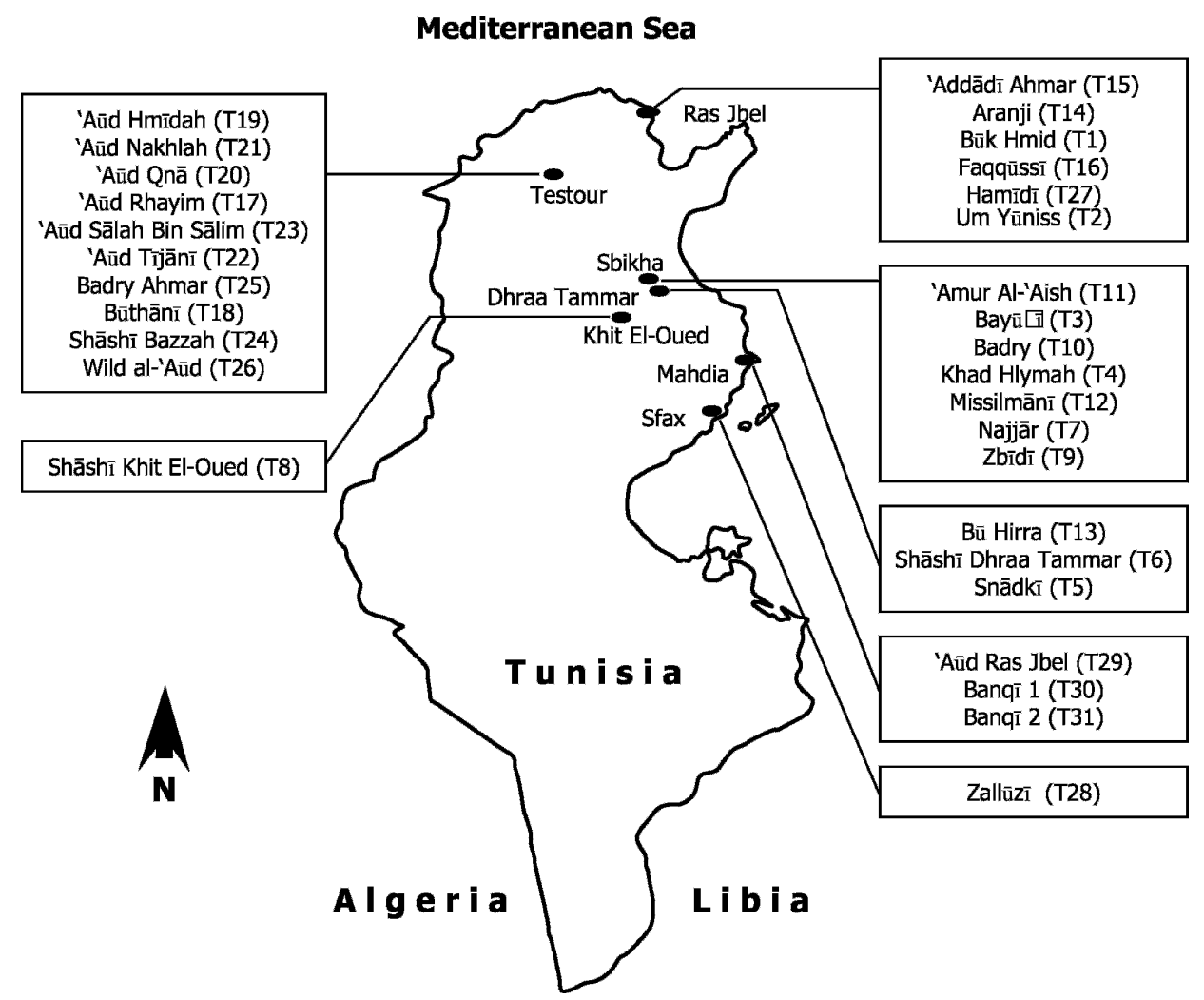

Fig. 1. Geographic origin of the 31 apricot cultivars sampled in Tunisia (Txx corresponds to the reference code of the cultivar). 
Table 1. Morphological characteristics of the 31 apricot cultivars obtained in Tunisia. ${ }^{\mathrm{z}}$

\begin{tabular}{|c|c|}
\hline Cultivar & Main characteristics \\
\hline T1 Būk Hmid & Early ripening, medium fruit size, trapezoidal, light orange flesh, red skin color, medium soft, bitter kernel \\
\hline T3 Bayūdsī & Early-medium ripening, large fruit, rectangular, white flesh, pinky skin color, soft, bitter kernel \\
\hline T5 Snādk̄̄ & Early-medium ripening, large fruit, rectangular, light orange flesh, no over color, soft, sweet kernel \\
\hline T6 Shāshī Dhraa Tammar & Early-medium ripening, very small fruit, rectangular, white flesh, weak over color, very soft, bitter kernel \\
\hline T7 Najjār & Early ripening, large fruit, triangular, yellow flesh color, weak over color, medium soft, sweet kernel \\
\hline T9 Zbīdì & $\begin{array}{l}\text { Early-medium ripening, medium fruit size, rectangular, light orange flesh, red skin color, } \\
\text { medium soft, sweet kernel }\end{array}$ \\
\hline T10 Badry & Very early ripening, small fruit, circular, yellow flesh, weak over color, soft, sweet kernel \\
\hline T11 'Amur Al-'Aish & Early ripening, large fruit, trapezoidal, orange flesh, red skin color, firm, bitter kernel \\
\hline T12 Missilmān̄̄ & Early-medium ripening, large fruit, rectangular, light orange flesh, red skin color, medium soft, sweet kernel \\
\hline T13 Bū Hirra & Early ripening, medium fruit size, trapezoidal, light orange flesh, weak over color, very soft, bitter kernel \\
\hline T18 Būthānī & Early-medium ripening, medium fruit size, trapezoidal, yellow flesh, red skin color, firm, bitter kernel \\
\hline T19 'Aūd Hmīdah & Medium ripening, medium fruit size, circular, yellow flesh, red skin color, firm, bitter kernel \\
\hline T20 ’Āùd Qnā & $\begin{array}{l}\text { Medium ripening, medium fruit size, trapezoidal, light orange flesh, red over color, } \\
\text { medium soft, sweet kernel }\end{array}$ \\
\hline T21'Aūd Nakhlah & Medium ripening, medium fruit size, circular, orange flesh, red skin color, medium soft, bitter kernel \\
\hline T22 ’Aūd T1jān̄̄ & Medium ripening, medium fruit size, circular, white flesh, weak over color, very soft, bitter kernel \\
\hline T23 'Aūd Sālah Bin Sālim & Medium ripening, large fruit, trapezoidal, orange flesh, no over color, medium soft, sweet kernel \\
\hline T24 Shāshī Bazzah & Late ripening, medium fruit size, circular, white flesh, pinky over color, soft, sweet kernel \\
\hline T25 Badry Ahmar & Early ripening, medium fruit size, circular, orange flesh, red skin color, soft, bitter kernel \\
\hline T26 Wild al 'Aūd & Medium ripening, medium fruit size, circular, orange flesh, weak skin color, firm, bitter kernel \\
\hline T27 Hamīdi & Early ripening, large fruit, trapezoidal, orange flesh, red skin color, soft, bitter kernel \\
\hline
\end{tabular}

${ }^{\mathrm{z}}$ Ripening period, fruit size, fruit shape, fruit color, fruit over color, fruit firmness, and kernel taste were characterized according to International Union for the Protection of New Varieties of Plants (UPOV) descriptors.

slight modification based on the augmentation of the concentrations (reduction by $1 / 4$ of the volumes used).

EcoRI primers were radioactively labeled using $\left[\gamma-{ }^{33} \mathrm{P}\right] \mathrm{ATP}$. PCR products were run on denaturing polyacrylamide gel $(5 \%)$ and exposed to X-ray films for $2 \mathrm{~d}$. After development, the autoradiographs were read separately by two persons and ambiguous markers were not recorded.

DATA ANALYSIS. AFLP polymorphic bands were scored as present or absent and were treated as symmetric (both presence and absence of bands were considered in the data analysis). The dissimilarity measure used was Gower's distance (Gower, 1971). When applied to symmetrical binary data, Gower's distance is the complement to one of the simple matching coefficients (Sokal and Michener, 1958). Hierarchical analysis based on Ward's method has been applied to establish a group structure between cultivars to minimize the internal variance within group. Principal coordinate analysis has been used to highlight the pairwise relationship between cultivars. Correspondence analysis has been performed to explore the relationship between cultivars and their subgroups with the primer combinations. A discriminant analysis has been applied on the defined subgroups to control their consistency.
All calculations were performed with either one of the programs, NTSYS-pc version 2.1 (Rohlf, 1994) or NCSS (2005 release; NCSS, Kaysville, UT). Detailed descriptions of the multivariate analyses used can be found in Sneath and Sokal (1973) and in Davis (1973).

\section{Results and Discussion}

Genetic Diversity. The five AFLP primer combinations revealed 295 unambiguous fragments, of which 203 were polymorphic and 92, monomorphic. A unique AFLP pattern for each of the 31 studied cultivars has been obtained, with an average of 82 polymorphic markers per cultivar, ranging from 125 (for Bayūdsis) down to 61 (for Najjār), which means that all the related cultivars are genetically different. Polymorphic markers by primer combination varied from 38 to 46 (Table 2). In all numerical analyses, only unique AFLP markers fingerprints were used to avoid the bias introduced by possible nonrandom over-weighting of some of them and the obvious artificial reduction of taxonomic distances between cultivars. The data matrix thus purged of all redundant markers was reduced to 167 unique polymorph fingerprints (Tables 2 and 3). 
Table 2. Number of polymorphic and monomorphic AFLP markers revealed with the five selected EcoRI-MseI primer combinations in 31 Tunisian apricot cultivars.

\begin{tabular}{|c|c|c|c|c|}
\hline \multirow{3}{*}{$\begin{array}{l}\text { AFLP primer } \\
\text { combinations }\end{array}$} & \multirow[b]{3}{*}{ EcoRI/MseI primer sequences } & \multicolumn{3}{|c|}{ Markers (no.) } \\
\hline & & \multicolumn{2}{|c|}{ Polymorphic } & \multirow[b]{2}{*}{ Monomorphic } \\
\hline & & Total & Repeated & \\
\hline E 32-M 36 & GACTGCGTACCAATTCAAC/GATGAGTCCTGAGTAAACC & 46 & 7 & 14 \\
\hline E $35-$ M 35 & GACTGCGTACCAATTCACA/GATGAGTCCTGAGTAAACA & 38 & 9 & 22 \\
\hline E $46-\mathrm{M} 40$ & GACTGCGTACCAATTCATT/GATGAGTCCTGAGTAAAGC & 38 & 4 & 20 \\
\hline E $38-\mathrm{M} 43$ & GACTGCGTACCAATTCACT/GATGAGTCCTGAGTAAATA & 41 & 4 & 15 \\
\hline
\end{tabular}

Genetic STRUCTURE. The diversity of the studied sample of northern and central Tunisian cultivars was approached by calculating a dendrogram from the matrix of Gower distances between pairs of cultivars, by the minimum variance (Ward) method, which prioritizes the compactness of clusters and emphasizes their separation, normally at an acceptable level in terms of the preservation of distances among cultivars. The cophenetic correlation between the matrix of distances implicit in this dendrogram and the original matrix of distances was 0.795 , with a probability less than 0.001 against the null hypothesis of a random clustering (Mantel's test, 5000 permutations), which means that this dendrogram preserves the structure of the matrix of distances. Two main clusters were evidenced at 0.60 dissimilarity (Fig. 2): group A with nine cultivars and group B with the 22 remaining cultivars. Each group was further divided in three subgroups at 0.40 dissimilarity level. Analysis of the data matrix highlighted a set of polymorphic markers specific to each of the two groups. Cultivars of group A revealed the highest number of polymorphic markers, their average reaching 86 markers, as compared with 66 markers for group B (Table 3).

The taxonomic structure was further investigated by two other numerical approaches, all based on the same matrix of pairwise distances: Principal coordinate analysis (PCoor) and medoid (nonhierarchical) partitioning (MP). PCoor consists on a representation of the dissimilarity among several cultivars in a reduced multidimensional $Q$ space. On the first three principal coordinates, preservation of the original pairwise distances is very good (cophenetic correlation of 0.908 ). The two main clusters of Ward's dendrogram were separated along the first coordinate, and the second disintegrated group A into its three subgroups (first two coordinates accounting for $47 \%$ of the variance of the system; Fig. 3). Notwithstanding the much smaller number of cultivars in group A, its scattering in several individualized subgroups was evidence of higher diversity in comparison with group B.

Superposition of a minimum spanning tree (MST) to the PCoor plot showed that the two main clusters were connected (by the "single linkage" method, which is equivalent to the MST) by two links (Fig. 3): 'A $\bar{u} d$ Nakhlah' (T21) (subgroup B2) from Testour articulated with 'Būthānì' (T18) and ' Aūd Rhayim' (T17) (subgroup A2), also from Testour; the second link is established through 'Najjār' (T07) and 'Snādkì' (T05) (subgroup B1) to the remaining cultivars of group A, especially 'Zbīdı' (T09) and 'Missilmānì' (T12) (subgroup A1), all of them from the Kairouan area. This indicates that "'Aūd Nakhlah,' as well as 'Snādk $\vec{\imath}$ ' and 'Najjār,' shared many markers with cultivars in both groups A and B.

Partitioning by Medoid is nonhierarchical instead of grouping cultivars in successively larger clusters, MP distributes the cultivars to the desired number of groups whose composition is determined by permutations of cultivars until their distances to the respective medoid were minimized. When this technique was applied to the studied Tunisian cultivars, their MP partition into six groups was similar to that obtained by Ward's hierarchical clustering at the 0.40 dissimilarity level (average distance within groups, 64.81; average distance to neighbor, 72.13; average silhouette, 0.0980). Only three elements of

Table 3. Total number of polymorphic bands detected with the five primer combinations (inside parentheses, number of unique fingerprints used in all calculations) in the 31 Tunisian apricot cultivars (Txx corresponds to the reference code of the cultivar).

\begin{tabular}{|c|c|c|c|c|c|}
\hline \multicolumn{2}{|l|}{ Group A } & \multicolumn{4}{|c|}{ Group B } \\
\hline Cultivar & Bands (no.) & Cultivar & Bands (no.) & Cultivar & Bands (no.) \\
\hline T8 Shāshī Khit El Oued & $118(88)$ & T2 Um Yūniss & $79(72)$ & T21 'Aūd Nakhlah & $100(81)$ \\
\hline T10 Badry & $103(78)$ & T5 Snādk̄̄ & $72(68)$ & T23 'Aūd Sālah Bin Sālim & $67(64)$ \\
\hline T11 'Amur Al-'Aish & $111(86)$ & T6 Shāshī Dhraa Tammar & $69(66)$ & T24 Shāshī Bazzah & $72(69)$ \\
\hline T12 Missilmān̄̄ & $108(83)$ & T7 Najjār & $61(58)$ & T25 Badry Ahmar & $67(62)$ \\
\hline T18 Būthān̄̄ & $124(96)$ & T14 Aranji & $64(62)$ & T27 Hamīdī & $63(60)$ \\
\hline \multirow[t]{3}{*}{ T28 Zallūzī } & $99(80)$ & T15 'Addādì Ahmar & $65(62)$ & T29 'Aūd Ras Jbel (Mahdia) & $66(63)$ \\
\hline & & T16 Faqqūssī & $71(68)$ & T30 Banqī 1 & $77(72)$ \\
\hline & & T19 'Aūd Hmìdah & $69(66)$ & T31 Banq1̄ 2 & $70(67)$ \\
\hline Mean value group A & $112(86)$ & \multicolumn{3}{|c|}{ Mean value group B } & $70(66)$ \\
\hline
\end{tabular}




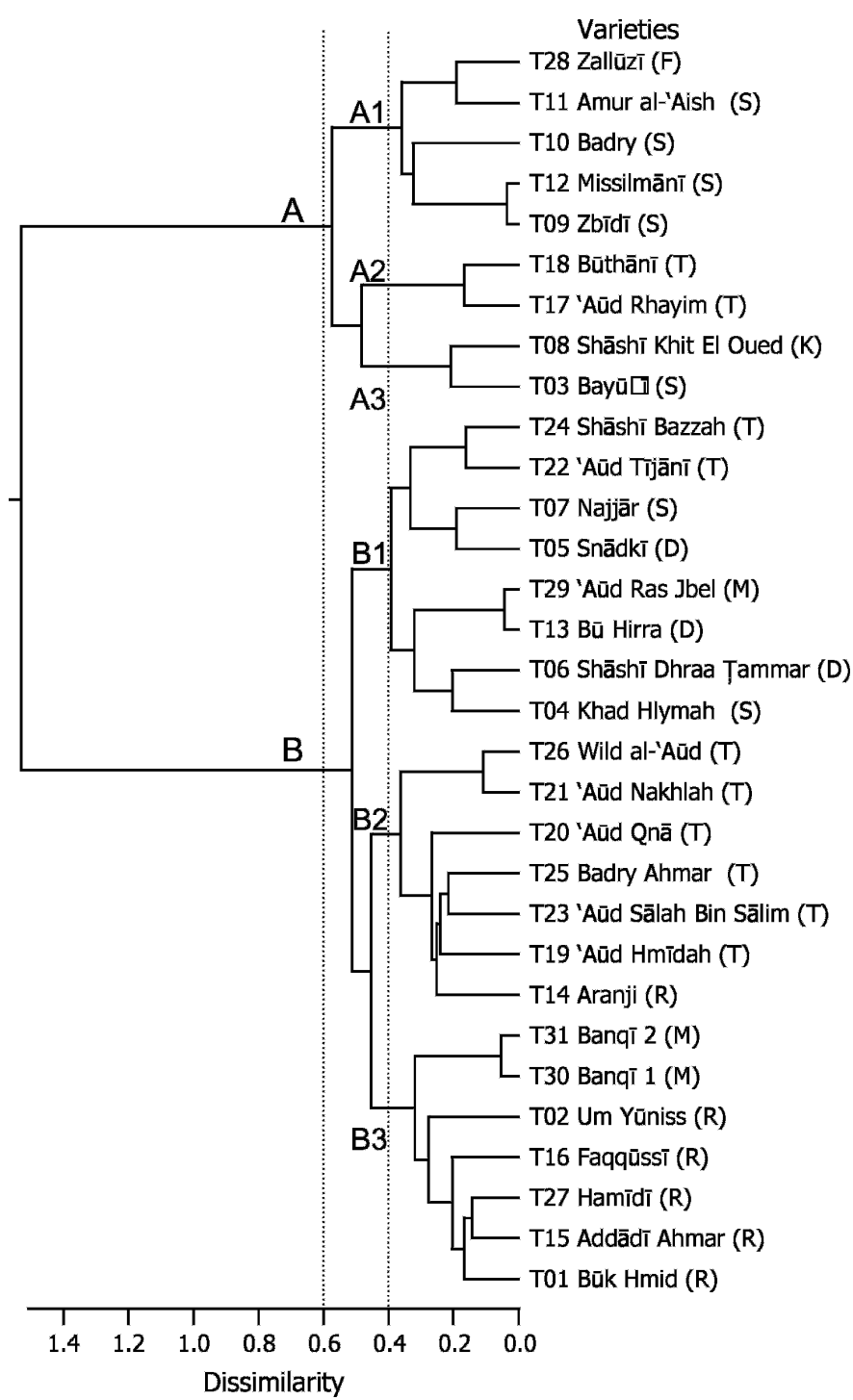

Fig. 2. Clustering of the 31 Tunisian apricot cultivars based on their AFLP profiles (Gower distances, Ward method); $\mathrm{R}=$ Ras Jbel, $\mathrm{T}=$ Testour, $\mathrm{S}=$ Sbikha, $\mathrm{D}=$ Dhraa Tammar, $\mathrm{K}=$ Khit El Oued, $\mathrm{M}=$ Mahdia, and $\mathrm{F}=\mathrm{Sfax}$.

group B were included in other subgroups ('Khad Hlymah', 'Najjāar', and 'Aranji' change to subgroup B3, although their very low silhouette values indicate that they could as well be included in subgroup B1).

The results obtained with the ordination analysis and the two clustering techniques agreed in the separation of the studied cultivars into two major groups and on their further subdivision. It seemed reasonable to use the subgroups thus obtained to investigate the relations between AFLP patterns and cultivars. First, a contingency table was produced by calculating for each cultivar the frequencies of markers in each primer combination, and correspondence analysis (CA) was performed (Fig. 4A). The first three factors account for $74 \%$ of the observed variance. The first factor separates group $\mathrm{A}$, with primer combinations E35M35, E33M40, and E32M36, from group B, with primer combinations E38M43 and E46M40.

Absolute frequencies of each AFLP primer combination were then calculated for the six subgroups of cultivars, and these data were submitted to CA. The first two factors were of

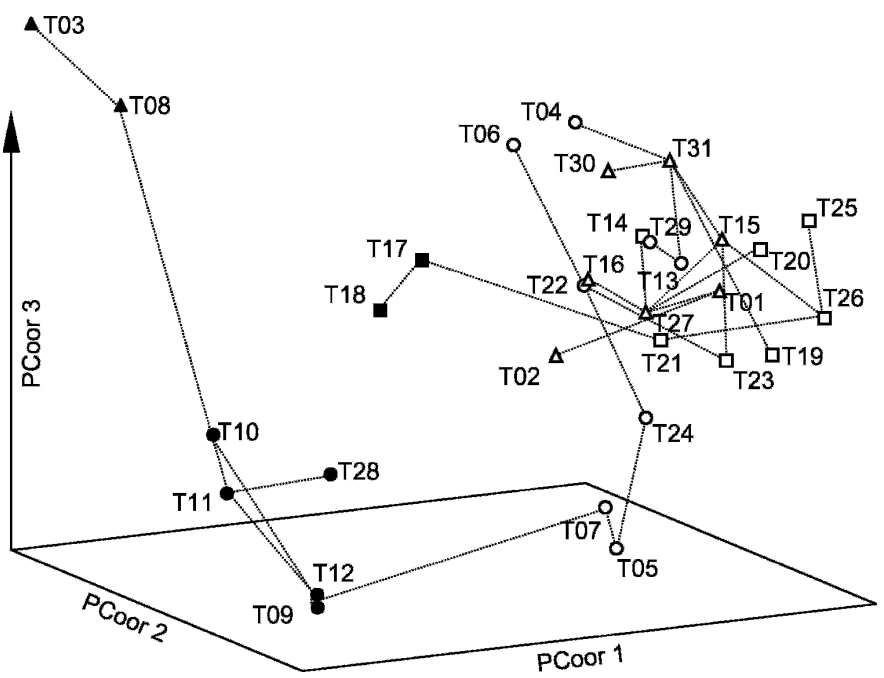

Fig. 3. Projections of the 31 Tunisian apricot cultivars on the first three principal coordinates, with superposed minimum spanning tree; group A (solid symbols), group B (open symbols), subgroup 1 (circles), subgroup 2 (squares), subgroup 3 (triangles). See Fig. 2 for group and subgroup definitions; PCoor = principal coordinates.

good quality and accounted for $86 \%$ of the variance (Table 4 ). The first factor separated cultivars in group A, with combinations E35M35, E33M40, and E32M36, from those in group B, with combinations E38M43 and E46M40. Factors 2 and 3 are related to discrimination of subgroups A and B (Fig. 4B). Thus, correspondence could be revealed when primer combinations and subgroups of cultivars previously identified were compared.

Distinctiveness between the two groups A and B was then confirmed by two correspondence analyses. By comparing the distribution of AFLP fingerprints by the two clusters of cultivars, 31 markers are found in group A only, and another 23 occur in group B only. Three markers were specific to group A (monomorphic in group B) and all were revealed by the E35M35 primer combination. Most of the markers which are monomorphic in group B and variable in group A, or monomorphic in A and variable in B, were obtained with the E46M40 primer combination. So both primer combinations (E35M35, E46M40) appeared determinant in the discrimination of the Tunisian apricot cultivars as shown by CA (Fig. 4). The division of the two groups in subgroups is mainly explained by the primer combinations (E32M36, E33M40, E35M35) for subgroups A and (E46M40, E38M43) for subgroups B.

RELATIONSHIP WITH GEOGRAPHIC ORIGIN. Cluster A includes the majority of cultivars from Sbikha and two from Testour completed with the single cultivars collected at Khit El Oued and Sfax. Cluster B includes the majority of the cultivars from Testour, two from Sbikha, and all the cultivars from Mahdia, Dhraa Tammar, and Ras Jbel (Fig. 2).

When the molecular diversity in relation to the geographic context is considered, two different patterns can be distinguished. On the one hand, the cultivars issued from the regions such as Ras Jbel (northeast), Dhraa Tammar (center), and Mahdia (center-east) showed a certain degree of homogeneity. All cultivars from Dhraa Tammar were clustered in the same subgroup B1, those from Ras Jbel in B3 except one located in subgroup B2, and those from Mahdia in B3 and B1. On the other hand, wider diversity can be found at Testour (northwest) with cultivars clustered in subgroups A2, B1, and B2 and 

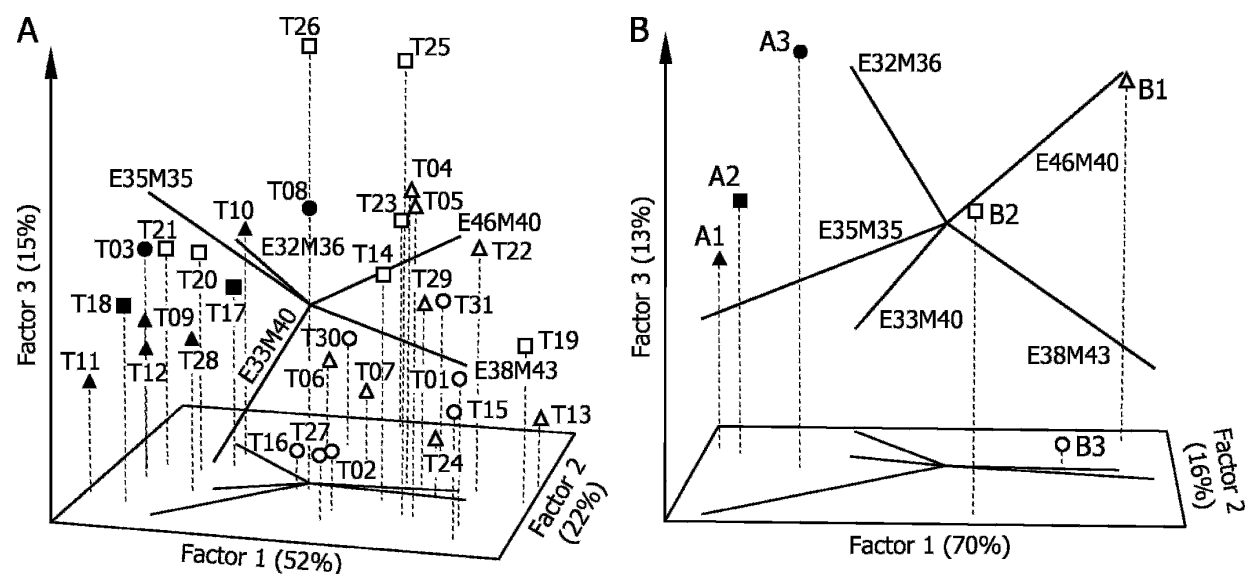

Fig. 4. Relations between apricot cultivars and primer combinations $(\mathbf{A})$ and between apricot subgroups and primer combinations (B) under correspondence analysis; group A (solid symbols), group B (open symbols), subgroup 1 (circles), subgroup 2 (squares), subgroup 3 (triangles). See Fig. 2 for group and subgroup definitions.

of their occurrence in the 31 cultivars, and these classes were pooled by pairs of equal numbers of presence and absence (e.g., markers present in 30 cultivars pooled with those absent in 30 cultivars; markers present in 29 cultivars pooled with those absent in 29 cultivars; etc.). Relative frequencies of marker presence were calculated in the resulting 15 sets of markers, thus producing 15 interval variables characterizing the $31 \mathrm{cul}-$ tivars. This new matrix was submitted to a multiple discriminant analysis with the cultivars distributed by the above-mentioned five a priori groups according to their geographic origin. The two first discriminant functions provided a

Sbikha (center) with cultivars clustered in subgroups A1, A3, and B1. The situation is rather different in the case of Sfax and Khit El Oued, with only one accession being available in each case even if their repartition remains consistent with the global repartition in the region.

With regard to the cluster analyses, a rough regional distribution can be perceived: most cultivars from Sbikha are found in group A, and in a similar manner most from Testour, Mahdia, and Ras Jbel occurred each in a subgroup of group B. This sketched geographic pattern was investigated by CA on contingency tables established with the frequencies of markers in the set of cultivars from each place (Fig. 5). The first three factors account for $67 \%$ of the observed variance. The results of a first CA indicated that the two single cultivars from Khit El Oued and Sfax were closer to those from Sbikha than from any other. Therefore, a second CA was performed after pooling the cultivars from these three locations (Sbikha, Khit El Oued, and Sfax). The first three factors account for $86 \%$ of the observed variance. The first factor separated the group of cultivars from Sbikha/Sfax/Khit El Oued, the second isolated those from Testour, and the third factor splits the groups from Testour, Mahdia, Dhraa Tammar, and Ras Jbel (results not shown).

To evaluate the consistency of this distribution by geographic origin, another analysis, based on the opposition of the cultivars according to their genetic distances, has been established. A set of numerical (interval) variables was defined using the information contained in the binary data matrix. The markers were distributed by classes according to the number

Table 4. Results of a correspondence analysis between AFLP primer combinations (5) and apricot cultivar subgroups (6) established on 31 Tunisian apricot cultivars.

\begin{tabular}{lccccc}
\hline Cultivar & \multicolumn{2}{c}{ Correlation } & Factor & \multicolumn{2}{c}{ Proportion of variance (\%) } \\
\cline { 2 - 3 } \cline { 6 - 7 } subgroup & Factor 1 & Factor 2 & no. & Individual & Cumulative \\
\hline A1 & 0.941 & 0.034 & 1 & 69.5 & 69.5 \\
A2 & 0.860 & 0.021 & 2 & 16.2 & 85.7 \\
A3 & 0.792 & 0.003 & 3 & 12.5 & 98.2 \\
B1 & 0.757 & 0.131 & 4 & 1.8 & 100.0 \\
B2 & 0.048 & 0.931 & - & - & - \\
B3 & 0.503 & 0.007 & - & - & - \\
\hline
\end{tabular}

good separation of the geographic groups, with only three misclassified cultivars (Table 5). Inspection of the misclassified cultivars suggests pooling those from Testour, Mahdia, and Dhraa Tammar in a single group. The resulting two discriminant functions were highly significant (respective probabilities of 0.001 and 0.019 ) and enabled the separation of the three groups without misclassified cultivars (Fig. 6).

Cultivars from Sbikha, Sfax, and Khit El Oued exhibited the highest numbers of specific markers, although these local sets might be heterogeneous, as they occur in both groups. Concurrently, cultivars from Ras Jbel, Mahdia, and Dhraa Tammar exhibited the lowest number of specific markers and seemed homogenous (Table 6). Thus, it has been possible to define some homogenous region based on the different areas of origin: northeast for Ras Jbel, northwest for Testour, center for Kairouan, Khit El Oued, and Sbikha, and center-east for Mahdia and Sfax.

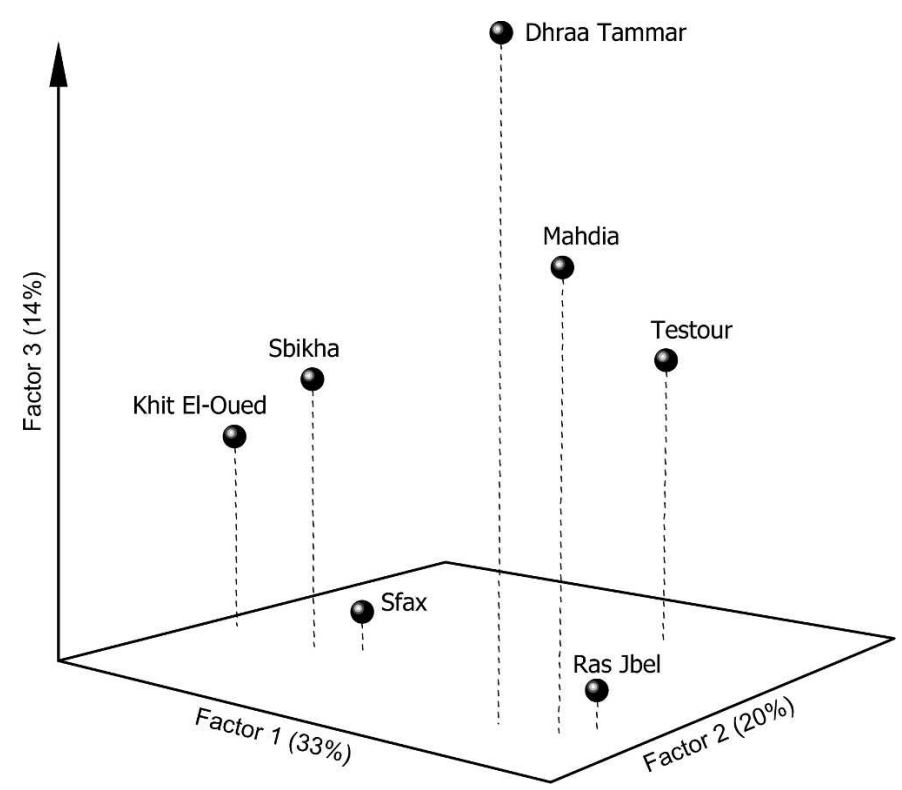

Fig. 5. Correspondence analysis based on contingency frequencies of AFLP markers among geographic groups of the 31 Tunisian apricot cultivars analyzed. 
Table 5. Results of a multivariate discriminant analysis concerning the classification of 31 Tunisian apricot cultivars with AFLP markers in relation with their geographic origin.

\begin{tabular}{lccrrrr}
\hline & & & \multicolumn{3}{c}{ Predicted group (\% probability) } \\
\cline { 5 - 7 } Function & Total proportion (\%) & Misclassified cultivars & & \multicolumn{3}{c}{ Sbikha, Khit } \\
(original group) & Dhraa Tammar & Mahdia & El Oued, Sfax & Ras Jbel & Testour \\
\hline 1 & 51.5 & T20 (Testour) & 0.0 & 87.0 & 0.0 & 0.0 \\
2 & 85.5 & T22 (Testour) & 57.9 & 0.8 & 0.3 & 0.0 \\
3 & 95.9 & T29 (Mahdia) & 13.1 & 36.4 & 0.0 & 0.0 \\
4 & 100.0 & & & & & \\
\hline
\end{tabular}

Reduction in classification error: $87.9 \%$.

The regional clustering highlighted that some regions were more isolated than others, such as the northeast and, to a lesser extent, the center-east. The center and the northwest regions presented the largest diversity expressed either by the number of subgroups or by the number of cultivars. Concerning group $\mathrm{A}$, it is present essentially in northwest and center with the exception of the cultivar from Sfax (center-east). Concerning group $\mathrm{B}$, it is present in all the regions, but a clear specialization has been observed, consisting in the exclusive presence of $\mathrm{B} 2$ in the northwest and B3 in the northeast, while B1 was widely spread in almost all regions. This suggests for group B a single introduction and an internal diversification and specialization in situ.

According to the dispersion mode of apricot through the country, propagation by grafting seems to be the rule at Ras Jbel (Carraut and Crossa-Raynaud, 1974), and their distribution to the south along the 'Sahel' in a region rather homogeneous from the climatic point of view (Crossa-Raynaud, 1960) could be at the origin of the similarities found with the cultivars from Mahdia. The reasons for the diversity found at Testour may be different. The majority of its cultivars belong to group B, except the two that make up subgroup A2 [these are morphologically different from all the other cultivars of Testour by their light flesh color and their relatively early ripening (Krichen et al., 2006)]. According to Carraut and Crossa-Raynaud (1974), there was a continuously evolving assortment of cultivars as a result of propagation by seeds, the best being preserved by

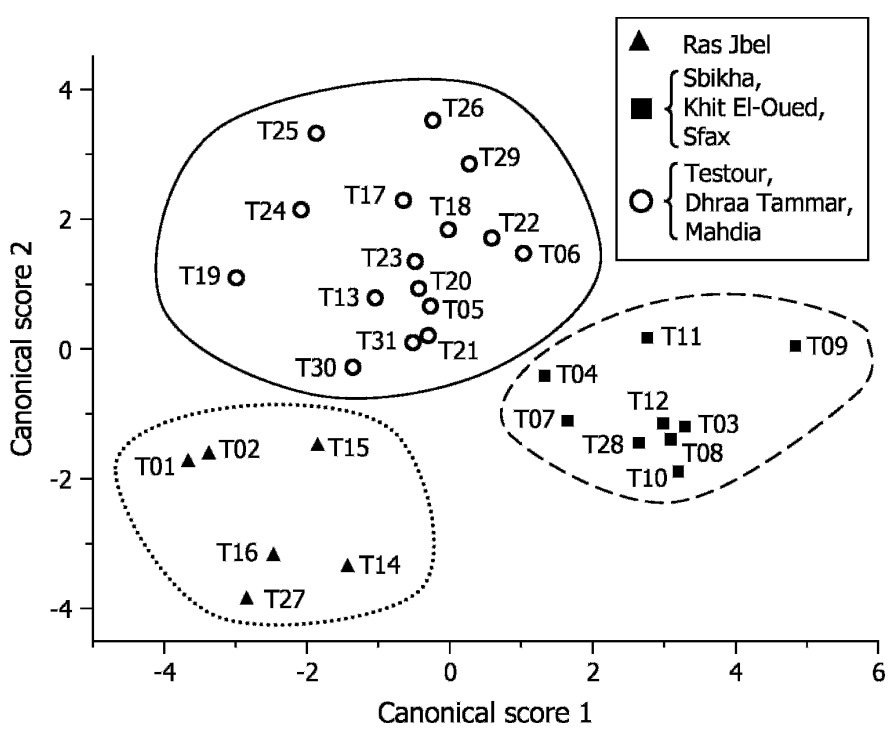

Fig. 6. Discriminant analysis performed on the 31 Tunisian apricot cultivars' AFLP fingerprints according to their geographic origin. grafting in this region. The diversity of apricots from Testour might thus be the outcome of old cultivation traditions where propagation by seed and by grafting have coexisted for centuries.

In synthesis, the Tunisian gene fund is issued from at least two major populations corresponding to groups $\mathrm{A}$ and $\mathrm{B}$, with a wider diversity clearly identified in group $\mathrm{A}$ in comparison with group B (Fig. 3). Concurrently, the subdivision of group A in distinct subgroups and the presence of cultivars from the northwest and the center and not from the northeast suggested a specialization within each region.

Exchanges of plant material between regions over time may contribute to explain the present situation. One of the most relevant points to have in mind is that fruit cultivation is relatively recent at Kairouan and its surroundings. Most of the cultivars from Sbikha were concentrated in group A, concurring in three subgroups with cultivars from the center, the northwest, and the center-east. The presence of the accession from Sfax within subgroup A3 with cultivars from Sbikha can thus be understood. Sfax is a traditional apricot culture area, which enclosed a notable diversity that has disappeared during the last decades (Carraut and Crossa-Raynaud, 1974). 'Badry', 'Amur Al-'Aish ', and 'Missilmānì' were referenced as cultivars from Sfax by Carraut and Crossa-Raynaud (1974). Thus, the wide diversity observed in the area of Kairouan can be related to the recent introduction of all the best cultivars found in other parts of the country in this new area.

Plant materials described in a previous article have in common a large number of Tunisian apricots with this work (Khadari et al., 2006), and they showed approximately similar clusters of the sampled cultivars. It evidenced that diversity is phyletically related, resulting from evolution of a single stock or of a number of very similar stocks. Information on the recent dispersion of the crop and testimonial older references (Carraut and Crossa-Raynaud, 1974; Crossa-Raynaud, 1960) pointed to a different picture, namely, that many cultivars from each region have been distributed in the country, either for studying their adaptation to other places or as a deliberate introduction of the best cultivars in newly cultivated areas, although in some places, the "traditional" cultivars still remain dominant.

Historical facts of Tunisian apricot genetic origin. Relative to the structure in two groups, Tunisian diversity could be related to different introductions. Two questions may thus be raised; namely, 1) how do the two main groups found among Tunisian apricots fit in the ecogeographic classification proposed by Kostina (1969), and 2) how did they come to this country?

The present diversity of Tunisian apricots should be understood as the outcome of several centuries with episodes of mass migrations and political or sociological changes. 
Table 6. Average frequency of AFLP markers per apricot cultivar relatively to geographic distribution (surveyed locations) and identified clusters (Ward's subgroups) established on the 31 Tunisian apricot cultivars analyzed.

\begin{tabular}{|c|c|c|c|c|c|c|}
\hline & \multicolumn{5}{|c|}{ Primer combinations } & \multirow[b]{2}{*}{ Markers (no./cultivar) } \\
\hline & E32M36 & E33M40 & E35M35 & E46M40 & E38M43 & \\
\hline \multicolumn{7}{|l|}{ Subgroups } \\
\hline A1 & 22.0 & 18.6 & 13.0 & 13.0 & 15.4 & 82.0 \\
\hline A3 & 24.5 & 18.5 & 14.0 & 16.5 & 17.0 & 90.5 \\
\hline B1 & 16.0 & 12.8 & 7.4 & 13.6 & 14.8 & 64.5 \\
\hline B2 & 16.3 & 12.1 & 10.6 & 13.0 & 15.0 & 67.0 \\
\hline \multicolumn{7}{|l|}{ Surveyed locations } \\
\hline Khit El Oued & 24.0 & 17.0 & 12.0 & 18.0 & 17.0 & 88.0 \\
\hline Sfax & 20.0 & 18.0 & 13.0 & 13.0 & 16.0 & 80.0 \\
\hline Sbikha & 21.3 & 17.0 & 11.4 & 13.1 & 14.7 & 77.6 \\
\hline Testour & 17.5 & 14.0 & 11.0 & 13.8 & 15.5 & 71.8 \\
\hline Dhraa Tammar & 16.7 & 13.3 & 7.7 & 14.3 & 15.3 & 67.3 \\
\hline
\end{tabular}

According to the historical facts, the first introduction of apricots in Tunisia could be attributed to Phoenician origins more than 2500 years ago according to the exchange of commercial products between the oriental and occidental Mediterranean basin. Later, the Romans contributed to the agricultural revolution, which was essentially based on cereals, olive (Olea europea L.), wine (Vitis vinifera L.), and fruit of secondary interest such as fig (Ficus carica L.), pear (Pyrus communis L.), and pomegranate (Punica granatum L.), which were represented on Roman mosaics (Slim, 2001). However, no particular interest was observed for apricot.

Elsewhere, Discoride and Columelle (around 50 AD) indicated that apricot was mentioned as "mailon armeniacon" (Armenian apple), that it may have arrived in Roman territories during the first century BC (Löschnig and Passecher, 1954), and it was extended around the Mediterranean Basin. Apricot was not native of Armenia, as only cultivated forms have already been described in this area, and no wild forms like those found in China were described there (De Candolle, 1886; Faust et al., 1998).

Relative to the apricot introduction in Tunisia directly from the Irano-Caucasian ecogeographic classification described by Kostina, several authors stated that it first took place with the Arabic colonization of the region (Bailey and Hough, 1975; Kostina, 1969). These original stocks were most probably carried to Spain shortly after. Some importance has been attributed to materials brought by Andalusian immigrants who established themselves in northern Tunisia following their mass eviction from Spain in the early 17th century (Carraut and Crossa-Raynaud, 1974; Valdeyron and Crossa-Raynaud, 1950). These apricots could be derived from that original stock after some centuries in culture, where propagation by seeds was a well-established practice and recommended for some soils (Ibn Al-Awam, 1145). Other possible means of introduction that should be contemplated were trade during the Ottoman rule [which seems to have led also to the introduction in Europe of Kostina's "European" ecogeographic type; see Faust et al. (1998)] and trans-Mediterranean trade, especially after the early 18th century. This is supported by Faust et al. (1998), considering that the Turkish apricots expressed a larger variability in comparison with the existing European cultivars which had been brought by Turks to eastern Europe since the 16 th century.

Thus, given their agronomic and morphologic characteristics, some Tunisian cultivars seem to be close to Kostina's "Irano-Caucasian" or to the "Mediterranean" group of Hagen et al. (2002). This classification was conducted on a morphological basis, and it would be certainly very interesting to assess the same germplasm with DNA markers.

These results were the first step to a more extensive analysis that will include more cultivars to cover all the apricot genetic diversity and to conclude more sound results with the inclusion of numerous and representative materials from all of the Mediterranean Basin, to elucidate the apricot history and its geographic distribution. As a sequel to the present work, new surveys should be made in the southern areas of apricot cultivation in Tunisia (Sfax, Gabes, Jerba, Gafsa, and the western oases) to sample more cultivars and to draw a clearer picture of the diversity of the Tunisian apricot germplasm, trying to apply the methodology to a wider range of samples from this country.

\section{Literature Cited}

Aranzana, M.J., J. Carbo, and P. Arùs. 2003. Using amplified fragment-length polymorphisms (AFLPs) to identify peach cultivars. J. Amer. Soc. Hort. Sci. 128:672-677.

Badenes, M.L., J. Martinez-Calvo, and G. Llàcer. 1998. Analysis of apricot germplasm from the European ecogeographical group. Euphytica 102:93-99.

Balta, F., T. Kaya, T. Yarelgaç, A. Kazankaya, M.F. Balta, and M.A. Koyuncu. 2002. Promising apricot genetic resources from the Lake Van region. Genet. Resources Crop Evol. 49:411-415.

Bailey, C.H. and L.F. Hough. 1975. Apricots, p. 367-383. In: J. Janick and J.N. Moore (eds.). Advances in fruit breeding. Purdue University Press, West Lafayette, IN.

Battistini, S. and S. Sansavini. 1991. Electrophoretic analysis of isozyme variability in apricot cultivars. J. Genet. Breed. 45:117-122.

Bernatzky, R. and S.D. Tanksley. 1986. Genetics of actin-related sequences in tomato. Theor. Appl. Genet. 72:314-321.

Byrne, H.D. and T.G. Littleton. 1989. Characterization of isozyme variability in apricots. J. Amer. Soc. Hort. Sci. 114:674-678. 
Carraut, A. and P. Crossa-Raynaud. 1974. L'amélioration des variétés d'abricotier en Tunisie. Ann. Inst. Natl. Recherche Agron. Tunis 47:1-33.

Crossa-Raynaud, P. 1960. Problèmes d'arboriculture fruitière en Tunisie. Ann. Inst. Natl. Recherche Agron. Tunis 33:39-63.

Davis, J.C. 1973. Statistics and data analysis in geology. Wiley, New York.

De Candolle, A. 1886. Origin of cultivated plants. 2nd ed. (reprinted in 1967). Hafner Publishing, New York.

De Vienne, D. 1998. . Les marqueurs moléculaires en génétique et biotechnologies végétales. Institut National de Recherche Agronomique, Paris.

Desprès, L., L. Gielly, B. Redoutet, and P. Taberlet. 2003. Using AFLP to resolve phylogenetic relationships in a morphologically diversified plant species complex when nuclear and chloroplast sequences fail to reveal variability. Mol. Phylogenet. Evol. 27: 185-196.

European Commission International Cooperation for Developed Countries. 2002. Final report 1998-2002. Prospection, characterisation and assessment of apricot genetic resources in the Mediterranean region for the production in arid and semi-arid areas. Centre International des Hautes Etudes Agronomiques Méditerranéennes (CIHEAM), Institut Agronomique Méditerranéen de Sarragosse (IAMZ), Audergon, Spain.

Faust, M., D. Suranyl, and F. Nyujto. 1998. Origin and dissemination of apricot. Hort. Rev. (Amer. Soc. Hort. Sci.) 22:225-266.

Geuna, F., M. Toschi, and D. Bassi. 2003. The use of AFLP markers for cultivar identification in apricot. Plant Breed. 122:526-531.

Gogorcena, Y. and D.E. Parfitt. 1994. Evaluation of RAPD marker consistency for detection of polymorphism in apricot. Sci. Hort. 59:163-167.

Gower, J.C. 1971. A general coefficient of similarity and some of its properties. Biometrics 27:857-871.

Hagen, L.S., B. Khadari, P. Lambert, and J.M. Audergon. 2002. Genetic diversity in apricot revealed by AFLP markers: Species and cultivars comparisons. Theor. Appl. Genet. 105:298-305.

Hormaza, J.I. 2001. Molecular characterization and similarity relationships among apricot (Prunus armeniaca L.) genotypes using simple sequence repeats. Theor. Appl. Genet. 104:321-328.

Hurtado, M.A., A. Westman, E. Beck, G.A. Abbott, G. Llàcer, and M.L. Badenes. 2002. Genetic diversity in apricot cultivars based on AFLP markers. Euphytica 127:297-301.

Ibn Al-Awam. 1145. Le livre de l'agriculture (translated by J.J. Clement Mullet, 1977). 2nd ed. Bouslama Editions, Tunis, Tunisia.

Khadari, B., L. Krichen, P. Lambert, M. Marrakchi, and J.M. Audergon. 2006. Genetic structure in Tunisian apricot populations multiplicated by grafting: A signature of bottleneck effects and ancient propagation by seedlings. Genet. Resources Crop Evol. 53:811-819.
Kostina, K.F. 1969. The use of varietal resources of apricots for breeding. Trud. Nikit. Bot. Sada 40:45-63.

Krichen, L. 2001. Prospection et identification des variétés autochtones d'abricotier (Prunus armeniaca L.) à Testour, Ras Jbel et Kairouan. Diplôme d'Etudes Approfondies (DEA), Institut National Agronomique de Tunis, Ariana, Tunisia.

Krichen, L., M. Ben Mimoun, and R. Hellali. 2006. Identification and characterization of Tunisian apricot cultivars. Acta Hort. 701(1):241-246.

Lambert, P., L.S. Hagen, P. Arus, and J.M. Audergon. 2004. Genetic linkage maps of two apricot cultivars (Prunus armeniaca L.) compared with the almond Texas $\times$ peach Earlygold reference map for Prunus. Theor. Appl. Genet. 108:1120-1130.

Löschnig, J. and F. Passecher. 1954. The apricot and its culture. Austrian Agronomic, Vienna, Austria.

Manubens, A., S. Lobos, Y. Jadue, M. Toro, R. Messina, M. Lladser, and D. Selenfreund. 1999. DNA isolation and AFLP fingerprinting of nectarine and peach varieties (Prunus persica). Plant Mol. Biol. Rptr. 17:255-267.

Pérez-González, S. 1992. Associations among morphological characters representing apricot germplasm in central Mexico. J. Amer. Soc. Hort. Sci. 117:486-490.

Ribeiro, O. 1986. Portugal, o Mediterrâneo e o Atlântico. 4th ed. Sá da Costa, Lisbon, Portugal

Rohlf, F.J. 1994. NTSYS-pc version 2.1. Exeter Software, Setauket, N.Y. Slim, H. 2001. La Tunisie antique: De Hannibal à Saint Augustin. Editions Menges, Paris.

Sneath, P.H.A. and R.R. Sokal. 1973. Numerical taxonomy. The principles and practice of numerical classification. Freeman, San Francisco.

Sokal, R.R. and C.D. Michener. 1958. A statistical method for evaluating systematic relationships. Univ. Kansas Sci. Bul. 38: 1409-1438.

Takeda, T., T. Shimada, K. Nomura, T. Ozaki, T. Haji, M. Yamaguchi, and M. Yoshida. 1998. Classification of apricot varieties by RAPD analysis. J. Jpn. Soc. Hort. Sci. 67:21-27.

Tavaud, M., A. Zanetto, J.L. David, F. Laigret, and E. Dirlewanger. 2004. Genetic relationships between diploid and allotetraploid cherry species (Prunus avium, Prunus $\times$ gondouinii and Prunus cerasus). Heredity 93:631-638.

Valdeyron, G. and P. Crossa-Raynaud. 1950. Les fruits de Tunisie. Ann. Inst. Natl. Recherche Agron. Tunis 23:65-82.

Vos, P., R. Hogers, M. Bleeker, M. Reijans, T. Van de Lee, M. Hornes, A. Frijters, J. Pot, J. Peleman, M. Kuiper, and M. Zabeau. 1995. AFLP: A new technique for DNA fingerprinting. Nucleic Acids Res. 23:4407-4414.

Zhebentyayeva, T.N., G.L. Reighard, V.M. Gorina, and A.G. Abbott. 2003. Simple sequence repeat (SSR) for assessment of genetic variability in apricot germplasm. Theor. Appl. Genet. 106:435-444. 